\title{
Doutorado em terapia ocupacional: desafios para a produção de conhecimento na área e sua consolidaçáo acadêmica ${ }^{1}$
}

Estar aqui comemorando o início do curso de doutorado em Terapia Ocupacional reflete o trabalho de muitas pessoas, de diferentes geraçôes e instituiçôes, que dedicaram e dedicam suas carreiras acadêmicas em prol da institucionalização da área de terapia ocupacional no cenário brasileiro, em geral, e no espaço acadêmico, em particular.

Nosso pequeno número foi e ainda é um entrave, a entrada da área oficialmente no sistema de pós-graduação nacional apenas em 2010 é um grande elemento dificultador no cenário nacional, mas temos juntado condiçóes e tensionado os sistemas para o reconhecimento da área de terapia ocupacional como campo de pesquisa e de produção de conhecimento.

A trajetória de formação de pesquisadores terapeutas ocupacionais no Brasil tem como característica o trilhar de percursos em campos de interface, uma vez que a possibilidade de constituição de conhecimento sobre terapia ocupacional efetivamente pouco se sustenta em outras áreas.

Assim, o curso de doutorado em terapia ocupacional nos traz o desafio de aprimorar, desenvolver e fundamentar o conhecimento em terapia ocupacional, de modo que possamos trazer bases teórico-metodológicas acerca do trabalho desenvolvido pela inserção social de diferentes grupos populacionais, pela maior autonomia e participaçáo de todos, pelo acesso aos bens sociais na sociedade brasileira. Fundamentar teoricamente o conhecimento em terapia ocupacional significa debruçar-nos diretamente sobre nossa estreita relação com as políticas sociais e a fundamentação sobre a função do técnico terapeuta ocupacional na sociedade. Esperamos e convidamos a todos os alunos e professores do Programa de Pós-graduação em Terapia Ocupacional (PPGTO) para que nossos estudos, produçóes e conhecimento daqui advindos se voltem para demandas concretas, de modo que, efetivamente, possamos pensar em estratégias e tecnologias de inserção social de diferentes grupos populacionais.

A trajetória acadêmica da terapia ocupacional no Brasil tem particularidades que a coloca em destaque no cenário internacional. Para além da possibilidade de invençóes de trabalhos, de intervenção, de mudanças significativas no cenário profissional, como vem ocorrendo na estreita relação entre Universidade e ação terapêutica-ocupacional nas políticas sociais, os pesquisadores terapeutas ocupacionais brasileiros têm trilhado o caminho da constituição de um conhecimento próprio, na especificidade da área e na sua autossuficiência enquanto campo de aplicação de tecnologias. Isso é bastante diferente em outros países, sendo que, em determinados locais, há uma "associação" com outras ciências e um sentido bastante estreito das possibilidades de desenvolvimento profissional. Ou uma pequena institucionalidade acadêmica da área, como vemos na realidade dos demais países latino-americanos. Aqui no Brasil, com características próprias, temos defendido o conhecimento em terapia ocupacional e nossas possibilidades de aprofundamento, adensamento e constituição de um campo eminentemente voltado para nossa especificidade.

Com essas características, temos algumas dificuldades em fazer circular nossas produçôes em nível internacional, o que as agências de pós-graduação e de pesquisa nos pedem hoje. O editorial sequente publicado neste volume exemplifica esta questão por meio da explicitação dos critérios do Conselho Nacional de Desenvolvimento Científico e Tecnológico (CNPq) para distribuição de bolsas de produtividade em pesquisa.

\footnotetext{
1 Discurso de abertura da aula inaugural do curso de doutorado em Terapia Ocupacional do Programa de Pós-graduação em Terapia Ocupacional da Universidade Federal de São Carlos, em 18 de setembro de 2015. A palestra magna sequente foi ministrada pelo Prof. Dr. André Rodacki, coordenador nacional da área de Educação Física, Fonoaudiologia, Fisioterapia e Terapia Ocupacional da Coordenação de Aperfeiçoamento de Pessoal de Nível Superior (CAPES).
} 
Para além das barreiras linguísticas, que é um desafio para toda a comunidade acadêmica atualmente, a área de terapia ocupacional do Brasil sofre, deste ponto de vista, com seu pioneirismo e alargamento de bases teóricas e de intervenção. Temos uma história eminentemente enraizada pelas características do desenvolvimento da terapia ocupacional brasileira, que, em seu percurso, tem uma pequena, embora crescente, entrada de modelos internacionais pré-estabelecidos. Esta autenticidade tem possibilitado a busca de caminhos para alicerçar conhecimento próprio e em consonância com as nossas reais demandas. Porém isto dificulta nosso diálogo internacional e, consequentemente, a efetivaçâo de publicaçôes internacionais. Entretanto, que possamos fazer desta fragilidade também a nossa força, por meio do desenvolvimento de estratégias de institucionalização acadêmica na defesa de nossas possibilidades e especificidades.

Temos certeza de que o curso de doutorado em terapia ocupacional é um marco nessa história. Demonstra a conjunçấo de esforços, de algumas geraçốes, pela institucionalizaçáo acadêmica da área. Não sabemos sobre o futuro, que é sempre incerto, mas temos certeza da relevância deste marco e dos nossos esforços coletivos para que este marco inicial, que comemoramos hoje, represente a efetiva institucionalização da área no âmbito da pós-graduação.

É neste lugar que o PPGTO-UFSCar se encontra, agora ainda mais indagado e desafiado por meio do curso de doutorado, pioneiro na América Latina. Está posto o desafio: que alcancemos a produçáo de conhecimento específica em terapia ocupacional e, com isso, avancemos na institucionalização acadêmica de nossa área. O que certamente reverberará em ampliação de postos de trabalhos, maior participação nas políticas sociais e, espera-se, intervenções voltadas para a inserção social e melhoria das condições de vida de muitos grupos populacionais alijados de sua vida social.

Pelo Programa, cabe um agradecimento especial ao Prof. Dr. André Rodacki, em seu trabalho de coordenação da área de Educação Física, Fonoaudiologia, Fisioterapia e Terapia Ocupacional da CAPES. Foi por meio de seu trabalho em prol de uma política de apoio às especificidades de cada subárea no interior da área 21 que a terapia ocupacional ganhou espaço e pôde apresentar sua especificidade e compromisso de contribuiçáo de desenvolvimento de conhecimento. Nosso sincero agradecimento e compartilhamento de uma política que fortaleça as especificidades desta área e de suas subáreas.

Agradecemos também todo o apoio institucional da UFSCar para a nossa criação e ampliação. Em especial, à Profa. Dra. Débora Morato Pinto, na Pró-Reitoria de Pós-graduação, pelo apoio às nossas demandas, particularmente ligadas aos Cadernos de Terapia Ocupacional, que tem estreita relação com o crescimento e o avanço do PPGTO.

Ainda, um agradecimento a todos nós docentes. Por fazermos um coletivo em prol da área de terapia ocupacional. Para além de nossas diferenças teóricas e ideológicas, permanecemos na certeza de que só cresceremos se for de forma articulada e coletiva.

E, por fim, bem-vindo a todos os alunos da primeira turma de doutorado em terapia ocupacional!

Que o caminho, apesar de árduo, possa ser frutífero! Nos levando à efetiva produção de conhecimento em terapia ocupacional.

\author{
Profa. Dra. Ana Paula Serrata Malfitano
}

Coordenadora do Programa de Pós-graduação em Terapia Ocupacional da Universidade Federal de São Carlos - PPGTO-UFSCar 